REVISTA DE DERECHO UNED, NÚM. 17, 2015

\title{
LAS DEMANDAS DE FILIACIÓN Y LA CORONA. REFLEXIONES SOBRE LA INVIOLABILIDAD REGIA. EL ACCESO A LA JURISDICCIÓN Y LA IGUALDAD ENTRE LOS HIJOS
}

\author{
THE DEMANDS ON THE FILIATION AND THE CROWN. \\ REFLECTION ON THE INVIOLABILITY. THE ACCESS TO \\ JURISDICTION AND EQUALITY BETWEEN THE CHILDREN
}

\section{ADORACIÓN GALERA VicTORIA}

Profesora Titular de Derecho Constitucional. Universidad de Granada

Resumen: El presente estudio pretende ofrecer un análisis de las cuestiones constitucionales que se han planteado con ocasión de las recientes resoluciones del Tribunal Supremo sobre las demandas de filiación presentadas frente a Don Juan Carlos I de Borbón. El foco de atención jurídico-constitucional se dirige sobre estas decisiones por cuanto la dimensión del asunto afecta a derechos fundamentales constitucionalmente consagrados y pone de relieve la concepción de la posición jurídica del titular de la Jefatura del Estado en asuntos concernientes a su ámbito privado o familiar. Se trata pues de examinar y valorar de forma crítica las últimas resoluciones del Tribunal Supremo en materia de filiación con el fin de analizar desde un punto de vista constitucional su alcance sobre la institución de la inviolabilidad regia y los derechos y fines constitucionales directamente implicados, esto es, la investigación de la paternidad (artículo 39.2 CE) el principio y derecho fundamental de igualdad (artículos 9.2 y $14 \mathrm{CE}$ ), y el derecho a la tutela judicial efectiva en su vertiente de acceso a la jurisdicción (artículo $24 \mathrm{CE}$ ).

Abstract: This paper aims to provide an analysis of constitutional issues raised during the recent Supreme Court decisions on a paternity 
action versus Don Juan Carlos I of Borbon. The focus of legal and constitutional attention is focused on these decisions because the case concerns fundamental rights guaranteed by the Constitution. It also emphasizes the concept of the legal position of the owner of the Head of State in matters concerning their private or family. It is therefore to examine and critically evaluate this recent Supreme Court decisions in order to analyze the scope of the institution of the inviolability and constitutional rights directly involved. In particular, they will be analyzed the determination of paternity (Article 39.2 of Spanish Constitution) the principle and fundamental right of equality (Articles 9.2 and 14 of Spanish Constitution), and the right to an effective judicial protection in regard to access to jurisdiction (Article 24 of Spanish Constitution).

Palabras clave: Inviolabilidad del Rey, investigación de la filiación, principio de prueba, acceso a la jurisdicción, igualdad ante la ley.

Keywords: Inviolability of the King, the investigation of filiation, signs of evidence, access to justice, equality before the Law.

Recepción original: 26/10/2015

Aceptación original: 4/11/2015

Sumario: I. Introducción. II. La inviolabilidad del Rey como casusa de inadmisión. III. La investigación de la filiación, el principio de igualdad entre los hijos y el derecho de acceso a la jurisdicción. III.1. El principio de prueba y la demanda presentada por don Alberto Solà. III.2. El principio de prueba y la demanda presentada por doña Ingrid Jeanne Sartiau. III.3. Voto particular al auto de la Sala civil del Tribunal Supremo de 27 de marzo de 2014. IV. Valoración final.

\section{INTRODUCCIÓN}

El análisis de los recientes pronunciamientos emitidos por la Sala Primera del Tribunal Supremo sobre las demandas de filiación no matrimonial interpuestas frente al ahora ex Jefe del Estado, Don Juan Carlos I de Borbón ${ }^{1}$, permite reflexionar sobre cuestiones que atañen

${ }^{1}$ Las decisiones judiciales recaídas en esta materia se centran en la sustanciación de dos procedimientos con orígenes procesales comunes, aunque retomados de forma sucesiva en el tiempo. Uno interpuesto por don Alberto Solà mediante escrito presentado el 15 de octubre de 2013 y otro a instancia de doña Ingrid Jeanne Sartiau mediante escrito fechado el 26 de junio de 2014, en ambos casos ante el decanato de los juzgados de Madrid. Con anterioridad los dos litigantes presentarían una demanda de filiación conjunta con fecha de 5 de octubre de 2012 que sería inadmitida a trámite por Auto de 9 de octubre de 2012 del Juzgado de Primera Instancia número 90 de Madrid. 
a aspectos esenciales del sistema constitucional. Y es que como se expone en el presente trabajo, las decisiones judiciales recaídas en esta materia no sólo reabren el clásico debate sobre la inviolabilidad regia (artículo 56.3 CE), sino que por su objeto, se pronuncian sobre el alcance de fines y derechos constitucionales a la investigación de la filiación y el principio de igualdad entre los hijos (artículo 39.2 CE y 14 y $9.2 \mathrm{CE}$ ), así como el derecho a la tutela judicial efectiva (artículo $24 \mathrm{CE}$ ) en su vertiente de acceso a la jurisdicción en el contexto de las demandas civiles de filiación.

En efecto, el sujeto frente al que se dirigen las acciones de filiación estudiadas orienta la interpretación judicial hacia una cuestión, la inviolabilidad regia, cuya concepción y alcance material ha suscitado desde su recepción constitucional, un destacable interés científico ${ }^{2}$. La inviolabilidad del Rey recogida en el artículo 56.3 CE, cuya plena comprensión requiere acudir a la institución del refrendo prevista en el artículo $64 \mathrm{CE}$, es una cuestión traída de nuevo a la luz de la interpretación jurídica en sede judicial. Como se analiza en las páginas siguientes, el debate jurídico se plantea sobre la delimitación material de esta prerrogativa atendiendo a la dialéctica entre una concepción absoluta o plena del instituto o una concepción relativa o limitada de la inviolabilidad más ajustada, a nuestro juicio, al conjunto de principios y valores constitucionales. El debate jurídico también alcanza otra delimitación, ahora temporal de dicha prerrogativa regia por cuanto las causas civiles objeto de la controversia judicial se refieren al Monarca abdicado.

Por otro lado, la discusión jurídica en sede jurisdiccional ofrece un marco para la reflexión acerca de los derechos y fines constitucionales a los que sirven los juicios de filiación. En particular, el derecho constitucional a la investigación de la filiación consagrado en el artículo 39.2 CE, del que podría deducirse el derecho a conocer el origen biológico ${ }^{3}$ y que, por su conexión con los artículos 10, 14 y 15

${ }^{2}$ Entre los primeros trabajos pueden consultarse, entre otros, A. MENÉNDEZ REXACH. La Jefatura del Estado en el derecho público español, Instituto Nacional de Administración Pública, Madrid, 1979; L. PORTERO GARCÍA. «La responsabilidad del Jefe del Estado», en Revista General de Derecho, núm. 448-449, 1982, págs. 4 y ss; págs. 226 y ss. y 466 y ss. M. ARAGÓN REYES, M. Dos estudios sobre la Monarquía Parlamentaria, Civitas, Madrid, 1990; M. HERRERO Y RODRÍGUEZ DE MIÑON. «La posición constitucional de la corona» en S. Martín-Retortillo Baquer (Coord.) Estudios sobre la Constitución española. Homenaje al profesor Eduardo García de Enterría, Vol. 3, 1991, págs. 1921 y ss. Del mismo autor «El Rey: artículo 56» en O. Alzaga Villaamil (dir.) Comentarios a la Constitución española de 1978, Edersa, Madrid, 1996-1999. T. V, págs. 39 y ss.

${ }^{3}$ La realidad actual ante las diversas formas de reproducción humana respaldan la propuesta formulada por Y. GÓMEZ SÁNCHEZ de incluir tal derecho a conocer el 
de la Constitución, adquiere una dimensión constitucional y no sólo civil o económica ${ }^{4}$. Como igualmente relevante se muestra en estos procesos la garantía de la igual posición entre los hijos con independencia de su filiación. El principio de igualdad planteado en este contexto cobra un particular significado a la hora de garantizar las obligaciones y los derechos derivados de las relaciones paterno-filiales ${ }^{5}$. Así ha sido sostenido desde una consolidada jurisprudencia ordinaria, constitucional e internacional y desde esa perspectiva es analizado este estudio.

Estas reflexiones se extienden además a una cuestión que incide directamente en el derecho fundamental a la tutela judicial efectiva garantizado en el artículo $24 \mathrm{CE}$. Y es que, en su vertiente de acceso a la jurisdicción, este derecho aparece como uno de los elementos centrales de la controversia judicial. La cuestión, en efecto, se deriva de la comprensión y aplicación del "principio de prueba» como requisito procesal necesario para la admisión a trámite de las demandas de filiación. De acuerdo con esta virtualidad, una consolidada jurisprudencia ordinaria y constitucional avala un criterio flexible del principio de prueba con el fin último de garantizar el derecho de acceso a la jurisdicción civil. Porque como es recordado, no se trata de que las demandas de filiación demuestren la veracidad de los hechos y datos aportados, sino que basta con que cumplan unas condiciones materiales mínimas, unos límites que justifiquen el juicio de filiación, que puedan inferir la «probabilidad» de la filiación reclamada.

Junto a estas cuestiones de indudable interés científico en el ámbito de los fines y derechos constitucionales, los casos estudiados presentan una circunstancia que confiere nuevos elementos para la re-

origen biológico en el texto del artículo 39.2 CE, en «Matrimonio y familia. Artículos 32 y 39 de la Constitución», en Revista de Derecho Político, núm. 36, 1992, págs. 207 y ss. en particular, págs. 220 y 221.

${ }^{4} \mathrm{Al}$ respecto, Vid. C VIDAL PRADO. «El derecho a conocer la filiación biológica (con especial atención a la filiación materna), Revista jurídica de Navarra, núm. 22, 1996, págs. 265 y ss. en particular, pág. 266.

${ }^{5}$ Junto a la invocación de las normas civiles y procesales aplicables, en estos procedimientos cobra protagonismo el derecho constitucional a garantizar la posición de igualdad de los hijos con independencia de su filiación (art. 39.2 CE y 108 CC), los efectos civiles de la filiación respecto a la determinación de los apellidos y las obligaciones de velar por los hijos y prestarles alimentos o la patria potestad (artículos 109 y 112 del CC). Al respecto, E. ROCA TRÍAS afirma que en el derecho de familia actual donde se rige por los derechos fundamentales de sus integrantes, «la protección otorgada por el artículo 39.2 CE a la familia "pasa por la protección de los derechos de los hijos», en "Familia y Constitución», Anuario de la Facultad de Derecho de la Universidad Autónoma de Madrid, núm 10, 2006, págs. 207 y ss. 
flexión crítica. Y es que, los cambios en la persona titular de la Jefatura del Estado acaecidos con posteridad a la presentación de ambas demandas de filiación y el subsiguiente reconocimiento de fuero jurisdiccional a los miembros de la Familia Real, modificará la sede judicial para el conocimiento de estos asuntos. En efecto, la abdicación del Rey Don Juan Carlos I a favor del Príncipe de Asturias como heredero de la Corona ${ }^{6}$ y la regulación prevista en el nuevo artículo 55 bis de la LOPJ, atribuye la competencia a las Salas de lo Civil y de lo Penal del Tribunal Supremo para conocer y tramitar las causas civiles y penales presentadas frente los miembros de la Familia $\mathrm{Real}^{7}$. Las demandas de filiación en trámite presentadas por Alberto Solà e Ingrid Jeanne Sartiau frente al Rey ya abdicado serán a partir de ese momento conocidas por este órgano jurisdiccional ${ }^{8}$. En definitiva, conviene detenerse en los argumentos jurídicos expuestos en las demandas y en los juicios de reclamación de filiación ejercitadas frente a Don Juan Carlos I de Borbón, l, Monarca abdicado, pero aún reinante, para valorar la solidez de la interpretación judicial a la luz de los derechos y garantías constitucionales en conflicto.

\section{LA INVIOLABILIDAD DEL REY COMO CAUSA DE INADMISIÓN}

Uno de los argumentos principales sobre los que se apoya de un modo particular, la demanda de filiación presentada por Alberto Solá y sobre la que se pronuncian tanto el juzgado de primera instancia

${ }^{6}$ Ley Orgánica 3/2014, de 18 de junio, por la que se hace efectiva la abdicación de Su Majestad el Rey Don Juan Carlos I de Borbón. Un estudio inmediato a la aprobación de esta ley, en A. TORRES DEL MORAL. «En torno a la abdicación de la Corona», en Revista Española de Derecho Constitucional, núm. 102, 2014, págs. 13 y ss.

${ }^{7}$ Conforme al apartado uno de este único artículo de la Ley Orgánica 4/2014, complementaria de la Ley de racionalización del sector público y otras medidas de reforma administrativa por la que se modifica la Ley Orgánica 6/1985, de 1 de julio, del Poder Judicial, se añade un nuevo artículo 55 bis a la LOPJ con la siguiente redacción: «Además de las competencias atribuidas a las Salas de lo Civil y de lo Penal del Tribunal Supremo en los artículos 56 y 57, dichas Salas conocerán de la tramitación y enjuiciamiento de las acciones civiles y penales, respectivamente, dirigidas contra la Reina consorte o el consorte de la Reina, la Princesa o Príncipe de Asturias y su consorte, así como contra el Rey o Reina que hubiere abdicado y su consorte». A nuestro juicio, no deja de ser sorprende desde el punto de vista técnico que tal disposición sea incluida en esta norma legal.

${ }^{8}$ En virtud de la disposición transitoria única de la Ley Orgánica 4/2014, se procederá a la remisión de las causas en curso a la sala competente del Tribunal Supremo. Vid. al respecto el examen sobre su competencia para conocer de estas demandas realizado por el Tribunal Supremo en el Fundamento de Derecho segundo del Auto de la Sala Civil de 28 de enero de 2014. 
como el ministerio fiscal en el estudio de la demanda, recae sobre en la virtualidad de la inviolabilidad regia como causa de inadmisión en estos procesos civiles. Como se adelantó en páginas anteriores, con ocasión de la sustanciación de estos procedimientos se reabre el debate entre la concepción plena o absoluta de la inviolabilidad y una noción relativa y limitada de esta prerrogativa a los actos exclusivamente realizados por el Monarca como titular de la Corona. No obstante, la dialéctica jurídica no queda limitada al clásico debate sobre el alcance material de la inviolabilidad, en virtud del cual el artículo 56.3 CE exonera de responsabilidad al Rey y exige el refrendo de sus actos conforme al artículo $64 \mathrm{CE}$, sino que alcanza además, a una nueva delimitación, ahora temporal de dicha prerrogativa regia por cuanto las acciones civiles de filiación se dirigen frente al ex titular de la Jefatura del Estado.

Desde una perspectiva material, la noción absoluta de la inviolabilidad regia se sostiene sobre la idea de que en el sistema democrático las monarquías carecen de poder político alguno y, por ello, de responsabilidad sobre sus todos actos, responsabilidad que es asumida de forma plena por otra institución del Estado mediante la institución del refrendo regio. Desde esta premisa, la inviolabilidad exonera y traslada la responsabilidad de todas las actuaciones (públicas y privadas) realizadas por el Monarca parlamentario en virtud de la institución del refrendo ${ }^{9}$. Desde otra perspectiva, la inviolabilidad debe ser entendida con un alcance limitado exclusivamente al ejercicio de las funciones propias de la Jefatura del Estado que son refrendadas por un órgano del gobierno, quien asume la responsabilidad del acto regio $^{10}$. La inviolabilidad no alcanza pues, a los actos privados o

${ }^{9}$ Esta posición ha sido firmemente defendida, entre otros autores por A. TORRES DEL MORAL en A. TORRES DEL MORAL y Y. GÓMEZ SÁNCHEZ. Estudios sobre la monarquía, Madrid, UNED, 1995, pág. 27.

${ }^{10}$ Sobre este instituto, entre otros, M. GARCÍA CANALES. "El refrendo en las monarquías», Revista de Estudios Políticos, núm. 212, 1977, págs. 235 y ss.; M. HERRERO Y RODRÍGUEZ DE MIÑON «Artículo 64. Refrendo de los actos reales», en O. Alzaga Villaamil (dir.) Comentarios a la Constitución española de 1978, op. cit. págs. 279 y ss.; C. FERNÁNDEZ- MIRANDA CAMPOAMOR. «La irresponsabilidad del Rey: El refrendo: evolución histórica y regulación actual», Revista de Derecho Político, núm. 44, 1998, págs. 225 y ss. B. OLIVER LEÓN «La irresponsabilidad como elemento sustancial de la monarquía» en, A. Torres del Moral (dir), Monarquía y Constitución, Constitución y Leyes, COLEX, 2001, págs. 343 y ss; J. M. ${ }^{a}$ PORRAS RAMÍREZ. «El principio de irresponsabilidad regia y el instituto del refrendo: Apuntes para un estudio en claves histórica y jurídico positiva», ibídem, pp.373 y ss. L. M. ${ }^{a}$ LÓPEZ GUERRA. "Las funciones del rey y la institución del refrendo», ibidem, págs. 389 y ss. P. J. GONZÁLEZ-TREVIJANO SÁNCHEZ. "Naturaleza jurídica del Refrendo», ibídem, págs. 403 y ss. I. TORRES MURO. «Refrendo y Monarquía», Revista Española de Derecho constitucional, núm. 87, 2009, págs. 43 y ss. 
particulares del Monarca que como tales no deben ser refrendados y se encuentra sometidos al derecho privado. Esta noción relativa o limitada según ha sido defendida por la doctrina, se ajusta mejor al marco de los principios y valores del constitucionalismo democrático y de Derecho ${ }^{11}$. Así concebida, la inviolabilidad en el Estado constitucional se muestra compatible con el principio democrático y con la plena efectividad del principio de igualdad de todas las personas ante la ley y del derecho a la tutela judicial efectiva.

Pues bien, ambas perspectivas aparecen expuestas en el juicio de filiación, en particular, en el trámite de admisión de la demanda. En efecto, según los argumentos defendidos por la demanda de filiación, una concepción restrictiva de esta prerrogativa permite iniciar el procedimiento de forma legítima y congruente con los mandatos y derechos constitucionales previstos en los artículos 14, 39.2 y 24 de la Constitución. El órgano judicial y el ministerio fiscal, en cambio, admiten una concepción amplia de la inviolabilidad extendida tanto a los actos que realice el Rey como titular de la Jefatura del Estado como a los propios de su ámbito familiar o privado. La inviolabilidad actuaría pues, como causa de inadmisión, sin que con ello se lesionara el derecho a la igualdad entre los hijos ni al derecho de acceso a la jurisdicción o al mandato constitucional de los poderes públicos de favorecer la investigación de la filiación.

En efecto, el titular del juzgado de primera instancia ante la falta de aforamiento del Monarca en aquel momento, se pronuncia y declara la inadmisión de la demanda ${ }^{12}$, basándose principalmente en el carácter inviolable del monarca en virtud del artículo 56.3 CE, inviolabilidad que según el órgano judicial alcanza tanto a sus actos personales como a los actos derivados del ejercicio de sus funciones ${ }^{13}$. A mayor abundamiento, el órgano judicial recuerda que la inviolabilidad y la irresponsabilidad del Rey son «cualidades consustanciales a

${ }^{11} \mathrm{Vid}$. al respecto, entre otros, L. PORTERO GARCÍA «La responsabilidad del Jefe

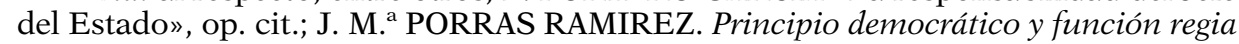
en la Constitución normativa Tecnos, Madrid, 1995, en especial págs. 175 y ss. P. BIGLINO CAMPOS. «La inviolabilidad de la persona del Rey y el refrendo de sus actos», en Jornadas de Derecho Parlamentario, 2001, Madrid, pág. 244 y 245, B. OLIVER LEÓN. Monarquía y Estado constitucional, Tecnos, Madrid, 2002; J. F. MERINO MERCHÁN. «Fuero judicial aplicable a la filiación extramatrimonial y a los actos testamentarios del Rey», Revista de Derecho Político, núm 71-72, 2008, págs. 380 a

${ }^{12}$ Auto el 30 de octubre de 2013 del magistrado-juez titular del Juzgado de Primera Instancia . $^{\circ} 34$ de Madrid

${ }^{13}$ El Auto de inadmisión se apoya en este punto en el auto de archivo dictado por la Sala Civil del Tribunal Supremo de 28 de febrero de 2006, sobre una acción de rectificación, y en el Auto de 9 de octubre de 2012 del Juzgado de Primera Instancia n. ${ }^{\circ} 19$ de Madrid inadmitiendo una demanda similar del mismo demandante.

(C) UNED. Revista de Derecho UNED, núm. 17, 2015 
la especial protección del Rey en el marco de los poderes del Estado y en su condición de símbolo de la unidad y permanencia del Estado». El recurso de apelación frente al motivo principal de esta resolución de inadmisión sería inmediato y los argumentos centrales del mismo el eje de las cuestiones constitucionales que plantea esta controversia.

Los fundamentos expuestos en el recurso son claros y de un indudable alcance constitucional. Frente a la interpretación amplia o absoluta realizada por el órgano judicial, la parte demandante solicita que se adopte una interpretación limitada o restrictiva de la inviolabilidad, entendida como prerrogativa sólo referida a los actos que el monarca ejerza como Jefe del Estado, sin que quepa su extensión a asuntos civiles o que entran dentro del ámbito privado o familiar. Una interpretación amplia del artículo 56.3 CE resultaría, según se expone en el recurso de la demanda, contraria al principio de igualdad previsto en el artículo $14 \mathrm{CE}$. Supone igualmente una vulneración del derecho a la tutela judicial efectiva prevista en el artículo $24 \mathrm{CE}$ al impedir el acceso a la jurisdicción para resolver una controversia familiar. Igualmente, la inadmisión de la demanda incurre, según la parte actora, en una vulneración del artículo 39 CE conforme al cual todos los hijos son iguales ante la ley con independencia de su filiación y constitucionaliza como derecho la investigación judicial de la filiación, contenidos que según se expone en el recurso, se encuentran alejados del artículo 56.3 CE. Por último, se invoca normas internacionales aplicables en esta materia, en particular los artículos 14 del Convenio Europeo de Derechos Humanos y el artículo 21 de la Carta Europea de Derechos Fundamentales.

La contestación del ministerio fiscal a estos argumentos jurídicos mantendrán la línea expuesta por el órgano judicial respecto del alcance del artículo $56 \mathrm{CE}$ y la no vulneración del principio constitucional a la igualdad y a la investigación de la filiación (artículos 14 y 39 $\mathrm{CE}$ ), El ministerio fiscal asume pues una concepción absoluta de la inviolabilidad y, por tanto, su extensión al ámbito privado o personal del monarca. Estaríamos, con sus palabras, ante «una excepción o corrección legal prevista en el texto constitucional y, por esta razón, legítima». Desde esta premisa, no cabría estimar una lesión del principio de igualdad conforme a las previsiones constitucionales citadas, ni de las normas internacionales aducidas por el demandante. Como tampoco cabría estimar una vulneración del artículo $24 \mathrm{CE}$ por cuanto, a juicio del ministerio público, «aun cuando no fuese aplicable al caso el artículo 56 de la Constitución, la demanda presentaba una serie de características que motivarían por sí solas su inadmisión». En este punto el argumento central para la inadmisión de la causa 
estaría ya, en la inexistencia del principio de prueba necesario para iniciar el procedimiento de filiación.

La abdicación de Don Juan Carlos I y la atribución de la competencia al Tribunal Supremo para conocer de estos asuntos cambiarán el centro de la argumentación jurídica. El Tribunal Supremo no entrará en el examen de estos planteamientos para deliberar sobre la admisión o inadmisión de las demandas de filiación presentadas frente al Rey abdicado ${ }^{14}$ pues, como advierte, estas «circunstancias sobrevenidas (..) han alterado por completo la base decisoria». Atendiendo pues, al momento procesal y a las circunstancias sobrevenidas en que entra a conocer el Tribunal Supremo, el principal motivo de discrepancia queda en un segundo plano de la interpretación jurídica. La declaración de admisión o no de la demanda se realizará en virtud de los requisitos procesales legalmente establecidos, con independencia de la inviolabilidad que, por sí sola, advierte el Tribunal Supremo, no impide el juicio de admisibilidad ${ }^{15}$.

A continuación, no obstante, la Sala admite que la Ley Orgánica 4/2014 no impide el ejercicio de acciones civiles frente al Rey abdicado y que la subsistencia de la inviolabilidad y la exención de responsabilidad alcanzaría a los actos realizados «durante el tiempo en que ostentare la Jefatura del Estado, cualquiera que fuere su naturaleza». En cambio, los actos que realice el Rey una vez abdicado sí podrán ser sometidos al control jurisdiccional, según la exposición de motivos de esta regulación orgánica ${ }^{16}$. Para el Tribunal Supremo la lectura de estos motivos de la ley ofrecen una delimitación temporal de la prerrogativa regia, a pesar de que la regulación del artículo 55 bis LOPJ no lo contempla expresamente y a pesar también de que lo que sí queda recogido es su competencia para sustanciar los «proce-

${ }^{14}$ Vid. al respecto los Fundamento de Derecho tercero y cuarto del Auto de inadmisión de 28 de enero de 2015 de la Sala Civil del Tribunal Supremo. Argumentos reiterados en el Fundamento Derecho segundo del Auto de admisión de 4 de febrero de 2015 de la Sala Civil del Tribunal Supremo.

${ }^{15}$ Fundamento de Derecho cuarto del Auto de inadmisión de 28 de enero de 2015 de la Sala Civil del Tribunal Supremo.

${ }^{16}$ Así lo establece la redacción la Exposición de Motivos de la Ley orgánica 4/2014 en su apartado IV: "Conforme a los términos del texto constitucional, todos los actos realizados por el Rey o la Reina durante el tiempo en que ostentare la Jefatura del Estado, cualquiera que fuere su naturaleza, quedan amparados por la inviolabilidad y están exentos de responsabilidad. Por el contrario, los que realizare después de haber abdicado quedarán sometidos, en su caso, al control jurisdiccional, por lo que, al no estar contemplado en la normativa vigente el régimen que debe aplicársele en relación con las actuaciones procesales que le pudieran afectar por hechos posteriores a su abdicación, se precisa establecer su regulación en la Ley Orgánica del Poder Judicial». 
dimientos en trámite». Finalmente, el órgano judicial subraya el momento en que ocurrieron los hechos que sostienen la demanda de filiación, anteriores a la proclamación del Rey abdicado.

La dialéctica jurídica sobre la inviolabilidad queda por tanto, soslayada por la vía de los hechos en las dos resoluciones judiciales en las que tiene ocasión de pronunciarse de nuevo el Tribunal Supre$\mathrm{mo}^{17}$. En ambos casos el máximo órgano judicial aduce por un lado, que las demandas de filiación se fundamentan en hechos presuntamente ocurridos incluso, antes de la proclamación de Don Juan Carlos 1 como sucesor en la Jefatura del Estado y, por otro, que las circunstancias sobrevenidas hoy, desplazan el instituto de la inviolabilidad del centro de la argumentación jurídica. El Tribunal Supremo identifica claramente el espacio temporal al que alcanza la inviolabilidad como prerrogativa que protege a la institución. Hubiese sido deseable sin embargo, un pronunciamiento sobre la delimitación material de esta prerrogativa, con el fin de esclarecer el correcto alcance de un instituto, el de la inviolabilidad regia, que por su vinculación jurídica con la institución de la Jefatura del Estado, merece ser desligada de los actos privados de su titular.

Una interpretación judicial adecuada al sistema constitucional actual, a los presupuestos esenciales de un Estado de Derecho que permitiese cohonestar la posición de las funciones del titular de la Corona como Jefe del Estado con el respeto a los derechos y principios constitucionales implicados hubiese sido un acierto judicial. En particular el derecho a la igualdad de todos en la aplicación judicial de la ley (artículo $14 \mathrm{CE}$ ), el mandato constitucional dirigido a los poderes públicos de realización de la igualdad real y efectiva (artículo $9.2 \mathrm{CE}$ ) y el derecho a la tutela judicial efectiva, en caso que nos ocupa, en su vertiente de acceso a la jurisdicción (artículo $24 \mathrm{CE}$ ). Entendido en este contexto y para el caso que nos ocupa, compartimos un aspecto clave de la argumentación del Tribunal Supremo. Y es que la inviolabilidad por si sola no impide el juicio de admisibilidad. Esto es, la prerrogativa de la inviolabilidad del Monarca traída al debate jurídico no supondría un obstáculo para la valoración de la admisión o inadmisión de la demanda, pues, lo realmente relevante es el cumplimiento de los fines constitucionales que informan las resolu-

${ }^{17}$ Para un análisis de los pronunciamientos del Tribunal Supremo en casos de reclamación de filiación frente al Rey en nuestra historia constitucional y sobre la competencia de la sala civil del Tribunal Supremo para conocer las demandas de filiación frente al monarca Vid. J. F. MERINO MERCHÁN. «Fuero judicial aplicable a la filiación extramatrimonial y a los actos testamentarios del Rey», op. cit. págs. 383 y ss. 
ciones judiciales sobre filiación y de los requisitos legalmente establecidos para la admisión de las demandas en esta materia.

\section{LA INVESTIGACIÓN DE LA FILIACIÓN, EL PRINCIPIO DE IGUALDAD ENTRE LOS HIJOS Y EL DERECHO DE ACCESO A LA JURISDICCIÓN}

El artículo 39.2 CE establece un mandato a los poderes públicos para que lleven a cabo una protección integral de los hijos y garantiza la igual posición de los hijos con independencia de la filiación. Igualmente, el precepto constitucional consagra un mandato al legislador para que haga posible la investigación de la paternidad. El precepto se completa con un tercer apartado donde se establece la obligación de los padres de prestar asistencia a los hijos habidos dentro y fuera del matrimonio. Se logra de este modo la «universalización» del principio de igualdad consagrado en el artículo $14 \mathrm{CE}$ cuyo alcance y extensión comprende a todos los hijos sin distinción ${ }^{18}$. Las posiciones de igualdad entre los hijos con independencia de su filiación deben ser pues garantizadas, sin que pueda encontrarse motivo alguno capaz de justificar una discriminación basada en el nacimiento fuera del matrimonio. La investigación de la filiación constituye en sí mismo un medio para garantizar la efectividad de los principios y fines constitucionales expresados en el texto constitucional ${ }^{19}$. Esto es, la Constitución garantiza la igualdad de los hijos al margen de su origen de filiación y pone al servicio de este derecho la investigación de la filiación como mecanismo para lograr su efectividad.

En este punto, conviene recordar que, a la luz de la doctrina del TEDH, asumida por la jurisdicción constitucional, una concepción amplia de la noción "vida familiar», equipara las familias establecidas sobre una relación matrimonial con las relaciones familiares de hecho ${ }^{20}$. En el marco de esta concepción amplia de vida familiar y, atendiendo al margen de apreciación de cada Estado, en la medida

${ }^{18} \mathrm{Al}$ respecto, puede consultarse J. ARCE Y FLOREZ VALDÉS. «El principio de igualdad de los hijos en el marco constitucional en relación a los hijos adoptados en forma simple», Liber Amicorum al profesor Ignacio de la Concha, Universidad de Oviedo, Servicio de Publicaciones, 1896, págs. 95 y ss. en particular, p 104.

${ }^{19} \mathrm{El}$ modo de lograrlo es autorizar la investigación de la filiación, aunque, como subraya R. CANOSA USERA. «su puesta en práctica conlleva eventuales sacrificios de la integridad o de la intimidad», en El derecho a la integridad personal, Lex Nova, Instituto Vasco de Administración Pública, Valladolid, 2006, págs. 259 y 260.

${ }^{20}$ Vid., entre otros, los casos Rasmussen c. Dinamarca, de 28 de noviembre de 1984; Keegan c. Irlanda, de 26 de mayo de 1994; Kroon c. Países Bajos, de 27 de octubre de 1994; Mikuliç c. Croacia, de 7 de febrero de 2002. 
en que existe «un vínculo directo entre el establecimiento de la paternidad y la vida privada», los procesos de filiación y el derecho de toda persona a buscar el esclarecimiento de su filiación queda amparado por el artículo 8 del $\mathrm{CEDH}^{21}$. Resulta además destacable de esta doctrina que la prohibición de discriminación entre los hijos tiene una clara proyección en la esfera patrimonial de la vida familiar y no sólo en el ámbito de las relaciones sociales o morales o en la formación cultural o la educación de los hijos. Las obligaciones de prestar alimentos o los derechos sucesorios son expresión de unos intereses patrimoniales que han de ser considerados ${ }^{22}$ y que en nuestro sistema aparecen consagrados en el artículo 39.2 y 3 de la Constitución ${ }^{23}$. La investigación de la filiación y propias las resoluciones judiciales recaídas en los diversos procedimientos de filiación ${ }^{24}$ se ponen directamente al servicio de esos fines constitucionales. Es más, la investigación de la filiación «guarda íntima conexión con la dignidad de la persona (art. 10.1 CE), tanto desde la perspectiva del derecho del hijo a conocer su identidad como desde la configuración de la paternidad como una proyección de la persona» (STC 138/2005, FJ 4). De ello se desprende la interpretación amplia que corresponde realizar a los órganos judiciales, tanto en la fase de admisión a trámite como en la de admisión de la prueba en estos procesos judiciales, para garantizar, en definitiva, el pleno ejercicio del derecho a la tutela judicial efectiva (artículo $24 \mathrm{CE}$ ).

${ }^{21}$ Sobre la aplicación de la doctrina del margen de apreciación en estos supuestos y las obligaciones que en todo caso deben salvaguardarse en los supuestos de investigación de la filiación Vid. el asunto Mikuliç c. Croacia, de 7 de febrero de 2002.

22 Así, Vid. el asunto Marckx c. Bélgica, de 13 de junio de 1979; Mazureck c. Francia, de 1 de febrero de 2000. Para una análisis de esta jurisprudencia Vid. M. PRESNO LINERA. Derecho europeo de familia, Cuadernos Aranzadi del Tribunal Constitucional núm. 22 (Estudios), Editorial Aranzadi, Pamplona. 2008, especialmente, págs. 39 a 41.

${ }^{23}$ Así lo considera expresamente la STC 7/1994, Fundamento Jurídico 2 donde se afirma que «en los supuestos de filiación, prevalece el interés social y de orden público que subyace en las declaraciones de paternidad, en las que están en juego los derechos de alimentos y sucesorios de los hijos, objeto de especial protección por el artículo 39.2 C. E., lo que trasciende a los derechos alegados por el individuo afectado, cuando está en juego además la certeza de un pronunciamiento judicial».

${ }^{24}$ Un estudio sobre los requisitos, modo de determinación y efectos de las acciones de reclamación e impugnación de la filiación, X. O'CALLAGHAN MUÑOZ. Investigación de la paternidad: acciones de filiación, investigación de la paternidad, prueba biológica, La Ley Actualidad, Madrid, 1994. Del mismo autor, «Acciones de reclamación e impugnación de la filiación. Investigación de la paternidad», en Compendio de Derecho Civil. Tomo IV. Derecho de Familia, Ministerio de Justicia, Madrid, 2012. Igualmente, sobre el régimen jurídico de las acciones de filiación M. GONZALES PÉREZ DE CASTO. La verdad biológica en la determinación de la filiación, Dykinson, Madrid, 2013. 
Y es que, como es recordado por la jurisdicción ordinaria, conforme a la finalidad perseguida por la norma constitucional respecto a la libre investigación de la filiación (artículo 39.2 CE), se produce la inclusión del "principio de prueba» como requisito necesario para la admisión de las demandas de filiación en el artículo 767.1 de la Ley de Enjuiciamiento Civil25. La presentación de prueba para iniciar los procesos de filiación es ineludible, actuando como un límite al ejercicio del derecho a la tutela juridicial efectiva (artículo $24 \mathrm{CE}$ ), en la medida en que su inexistencia impide el acceso a la jurisdicción. Pero, precisamente por el efecto que produce respecto del ejercicio del derecho constitucional a la tutela judicial efectiva, la jurisprudencia ordinaria ha venido realizando una interpretación amplia o flexible de este requisito procesal. Por tanto, los hechos alegados y presentados como prueba para admitir una demanda de determinación o impugnación de filiación se flexibilizan ${ }^{26}$, si bien éstos deberán cumplir unas condiciones materiales mínimas, unos límites que justifiquen el juicio de filiación que actúan como «una barrera a demandas carentes de todo fundamento» (STC 7/1994/FJ 4). Esto es, como reitera la jurisprudencia constitucional, la Constitución, mediante el artículo 39.2 CE «no incorpora un derecho incondicionado que permita, en todo caso, y con independencia de la concurrencia o no de circunstancias que lo justifiquen o desaconsejen, la averiguación de la identidad de un progenitor» (STC 116/1999/FJ 15). Por el contrario, un adecuado entendimiento del contenido constitucional sobre la investigación de la filiación y, por su conexión, de la garantía del acceso a la jurisdicción conduce a un sistema que, en ningún caso, permite «el planteamiento y la obligada sustanciación de acciones que resulten absolutamente infundadas» (STC 273/2005/FJ 7).

${ }^{25}$ Según esta norma «En ningún caso se admitirá la demanda sobre determinación o impugnación de la filiación si con ella no se presenta un principio de prueba de los hechos en que se funde» Fundamento de Derecho quinto del Auto de inadmisión de 28 de enero de 2015 de la Sala Civil del Tribunal Supremo.

${ }^{26}$ Como recuerda la Sala Civil del Tribunal Supremo en el Fundamento de Derecho quinto del Auto de inadmisión de 28 de enero de 2015, el principio de prueba se cumple con la presentación de fotografías (sentencias de 12 de noviembre de 1987, 21 de mayo de 1988 y 21 de diciembre de 1989), la declaración escrita de un cura párroco (sentencia de 19 de enero de 1990) o unas declaraciones de terceras personas ante notario (sentencias 20 de julio de 1990 y 3 de diciembre de 1991), sino también mediante la «alegación inicial de pruebas que puedan ser corroboradas en fase probatoria» (sentencia de 3 de junio de 1988) o la "oferta de practicar determinadas pruebas en el momento adecuado", sin necesidad de acompañar un documento al respecto (sentencias de 3 de diciembre de 1991, 20 de octubre de 1993 y 2 de febrero de 2006). 
La cuestión sobre la admisibilidad de las demandas de filiación requiere por tanto, soportar el juicio del órgano judicial acerca de la razonabilidad y el fundamento de la seriedad de la demanda. En este momento procesal, no se trata de probar la veracidad de los hechos, sino de aportar un "principio de prueba» en la demanda, esto es, aquellos datos, fotografías, declaraciones testificales o documentos que acrediten "la seriedad de la pretensión», aquellas circunstancias o acontecimientos que de forma razonable puedan inferir la "probabilidad» de la filiación reclamada. Así puede constatarse en las dos demandas presentadas frente a Don Juan Carlos I de Borbón, cuyo examen sobre la admisión o inadmisión a trámite ofrece itinerarios procesales distintos, atendiendo a las circunstancias concurrentes y condiciones que actúan sobre cada caso, aunque el resultado de la deliberación del órgano judicial sobre el contenido de la demanda resultara finalmente idéntico. Analicemos los argumentos jurídicos expuestos sobre esta cuestión para resolver ambos casos pues, como se ha recordado, las decisiones judiciales son adoptadas en un sentido diferente.

\section{III.1. El principio de prueba y la demanda presentada por don Alberto Solà}

En el caso de la demanda presentada por Alberto Solà, las razones expuestas por el ministerio fiscal para impedir la admisión a trámite son claras y precisas. Por un lado, argumenta la inexistencia del principio de prueba requerido por la ley atendiendo al relato de los hechos o circunstancias narrados en la demanda que, a su juicio, son meras hipótesis carentes de veracidad y validez a los efectos de acreditar mínimamente la seriedad o fundamento de la acción de filiación ${ }^{27}$. Por su parte, las razones del Tribunal Supremo para inadmitir a trámite de esta demanda por incumplir el requisito del «principio de prueba» son expuestas de una forma igualmente clara. Por un lado se argumenta la falta de presentación de los documentos e informes alegados en la demanda con los que se pretende fundamentar la veracidad de los hechos ${ }^{28}$. En segundo lugar, se advierte que el contenido real de los documentos e informes aportados no se corresponde con el contenido alegado como soporte de la demanda (en particular en lo

${ }^{27}$ Vid. Fundamento de Derecho sexto del Auto de inadmisión de 28 de enero de 2015 de la Sala Civil del Tribunal Supremo.

${ }^{28} \mathrm{Al}$ respecto, vid. el Fundamento de Derecho sexto, apartados 1), 3), 5) y 6) del Auto de inadmisión de 28 de enero de 2015. 
relativo a las pruebas de $\mathrm{ADN})^{29}$. En tercer lugar, la inadmisión de la demanda se apoya en la discordancia de los resultados de las pruebas de ADN aportadas por el demandante respecto de los aportados por Ingrid Jeanne Sartiau, quien expresamente se desvincula de las pruebas y documentos presentados en la demanda ${ }^{30}$ y que excluye que entre ambos demandantes exista una relación de parentesco.

Sobre la base de estos argumentos y dada la inexistencia de datos o indicios documentales objetivos y suficientes, la Sala de lo Civil del Tribunal Supremo considera que la demanda presentada por el Sr. Solà, no expone un «relato de hechos mínimamente coherente y razonablemente verosímil » ${ }^{31}$ que puedan constituir el "principio de prueba» necesario para sostener la acción de filiación. Esta decisión judicial será no obstante objeto de un recurso de amparo ante el Tribunal Constitucional por presunta lesión del derecho a la tutela judicial efectiva (artículo $24 \mathrm{CE}$ ). El Tribunal Constitucional inadmitirá el recurso apoyándose en un doble argumento: por un lado considera que no se han agotado los medios de impugnación existentes en la vía judicial previa y, por otro, en la inexistencia de lesión de un derecho susceptible de amparo constitucional ${ }^{32}$. Es posible que la cuestión controvertida sea trasladada al ámbito de la jurisdicción internacional por presunta lesión del artículo 14 del Convenio Europeo de Derechos Humanos que consagra la igualdad entre los hijos sin distinción alguna por razón de nacimiento, según se invocó en el escrito de la demanda. En todo caso, convendría recordar que las reclamaciones de filiación, por su conexión con la vida privada, son incluidas en el marco de protección del artículo 8 del Convenio.

${ }^{29}$ Según el Tribunal Supremo «no sólo no se aporta los documentos e informes que se dice que se aporta sino que, además, se ocultan datos voluntariamente». Fundamento de Derecho sexto, apartado 2) del Auto de inadmisión de 28 de enero de 2015.

${ }^{30}$ Según se afirma en el Auto, conforme al documento aportado por la Sra. Ingrid Jeanne Sartiau «el mismo doctor que practicó la prueba cuyo resultado fue ese $90{ }^{\prime} 874 \%$ se desdice unos días más tarde para concluir que "probablemente no son medio hermano y media hermana (solo 35\%) y que no están emparentados en primer grado»». Fundamento de Derecho sexto, apartado 4), del Auto de inadmisión de 28 de enero de 2015.

${ }^{31}$ Fundamento de Derecho sexto, apartado 7) del Auto de inadmisión de 28 de enero de 2015.

${ }^{32}$ Respecto al primer motivo para la inadmisión mediante Providencia de 5 de mayo de 2015, la Sección Tercera de la Sala Segunda del Tribunal Constitucional precisa el incidente de nulidad de actuaciones previsto en el artículo 241.1 LOPJ como cauce previo a la inicio de la vía de amparo. Respecto al segundo motivo, recuerda el contenido del artículo 44.1 de la LOTC como requisito necesario para la sustanciación del recurso ante el Tribunal Constitucional. 


\section{III.2. El principio de prueba y la demanda presentada por doña Ingrid Jeanne Sartiau}

A diferencia del caso antes expuesto, la demanda de filiación presentada por Ingrid Jeanne Sartiau sería admitida a trámite por la Sala Civil del Tribunal Supremo por estimar cumplido suficientemente el principio de prueba exigido por la ley. Para el órgano judicial los documentos aportados en la demanda, en particular la declaración notarial de la madre de la demandante y la alegación de tener contactos con personas que afirman ser familiares del demandante, constituyen un principio de prueba suficiente para estimar su razonabilidad y fundamento e iniciar la investigación de la filiación. Para ello, el órgano judicial parte de la consideración flexible de este requisito procedimental como instrumento «destinado a preservar la seriedad» de los procesos de filiación y filtro de peticiones «absolutamente infundadas o caprichosas» ${ }^{33}$. De la aplicación al caso concreto de esta consolidada jurisprudencia el Tribunal Supremo considera cumplido el principio de prueba a pesar de que estima insuficientes hoy los medios de prueba presentados ${ }^{34}$, y resuelve admitir a trámite la demanda de reclamación de filiación. No obstante, esta decisión judicial sería recurrida por las dos partes en el proceso ${ }^{35}$, lo que permitirá al Tribunal Supremo revisar su posición inicial, estimando el recurso de reposición presentado por la representación de Don Juan Carlos I de Borbón y dejando sin efecto el auto anterior de admisión a trámite de la demanda.

En efecto, el Tribunal Supremo reexamina el relato de los hechos y circunstancias de lugar y tiempo que fueron valorados en su día como un principio de prueba suficiente para estimar la seriedad y razonabilidad de la demanda ${ }^{36}$, advirtiendo una serie de contradiccio-

${ }^{33}$ En este contexto, recuerda su propia doctrina sobre la consideración indiciaria del principio de prueba, bastando con que se presente como base fáctica o fundamentación suficiente de la credibilidad o verisimilitud de la demanda. En particular las SSTS 239/1999, de 22 de marzo; 502/2000, de 18 de mayo; STS 738/2004, de 12 de julio y 59/2006, de 3 de febrero.

${ }^{34}$ Vid. Fundamento de Derecho cuarto del Auto de la Sala Civil del Tribunal Supremo de 4 de febrero de 2015.

${ }^{35}$ El 12 de febrero de 2015, la representación procesal de doña Ingrid Jeanne Sartiau interpuso recurso de reposición contra el auto de admisión de la demanda ante la falta de pronunciamiento en cuanto a la prueba anticipada solicitada para la determinación de la filiación. Por su parte, la representación procesal de Don Juan Carlos I de Borbón interpuso recurso de reposición contra el auto de admisión de la demanda al entender que la parte actora no había aportado con la demanda un principio de prueba suficiente para su admisión a trámite.

${ }^{36}$ Vid. al respecto, Fundamento de Derecho primero, apartado 1 del Auto de 27 de marzo de 2015, de la Sala Civil del Tribunal Supremo de estimación del recurso de reposición formulado contra la admisión de la demanda de filiación. 
nes que conducen a un pronunciamiento en sentido contrario. Para el órgano judicial la actuación posterior de la demandante han reducido el principio de prueba «e incluso, la propia demanda y su escrito de ampliación, al más completo vacío» ${ }^{37}$. Dadas las nuevas circunstancias y advertidas serias contradicciones con ocasión del recurso de reposición ${ }^{38}$, la demanda es calificada como «falsa, frívola y torticera». La nueva decisión judicial revisa el sentido de la anterior y considera que «la demanda carece por completo de verosimilitud o seriedad, incumpliendo así las exigencias del artículo 767.1 LEC ${ }^{39}$. En consecuencia, el tribunal determina no continuar con un proceso iniciado únicamente con el fin de obtener la prueba biológica, petición que afirma, «no guarda adecuada proporción con la intromisión que conlleva en la intimidad y la integridad física o moral del afectado por ellas ni con la finalidad a la que sirve». En definitiva, a juicio del órgano judicial no existen indicios suficientes para practicar la prueba solicitada, ni resulta necesaria para determinar una filiación «meramente inventada por quien formula la acción» ${ }^{40}$. La falta de seriedad o credibilidad de la demanda advertida tras su admisión a trámite impide continuar con el proceso y, por tanto, desestimar la petición formulada por la actora respecto a la práctica de la prueba

${ }^{37}$ En palabras del Tribunal Supremo «la situación ha cambiado de tal forma que aquello que se admitió como principio de prueba ha dejado de serlo por la actuación de la parte demandante, a la que esta Sala no puede permanecer indiferente, hasta el punto de reducir ese principio de prueba, e, incluso, la propia demanda y su escrito de ampliación, al más completo vacío». Fundamento de Derecho primero, apartado 3 del Auto de la Sala Civil del Tribunal Supremo de 27 de marzo de 2015.

${ }^{38}$ Según aprecia, las declaraciones y manifestaciones realizadas por la demandante difieren de las afirmaciones de su madre contenidas en el acta notarial que sirvió como principio de prueba. Como afirma el Tribunal Supremo «no es que los relatos difieran en cuestiones de detalle; es que se trata de dos versiones excluyentes por incompatibles». Las versiones de madre e hija son, advierte el Tribunal Supremo, "radicalmente diferentes en cuanto al tipo de relación entre el demandado y la madre de la demandante, hasta el punto de que la versión alternativa a la de la demanda tampoco es coincidente, porque tan pronto se sitúa el comienzo de la relación en Bélgica como se sitúa en Francia. (Fundamento de Derecho segundo). Apreciación que se mantiene y verifica en los fundamentos de derecho del auto citado, respecto la época y circunstancias en que la demandante conoció quien era su padre (Fundamento de Derecho tercero) y en la entrevista en "Casa Lucio» (Fundamento de Derecho cuarto). Auto de 27 de marzo de 2015 de la Sala Civil del Tribunal Supremo.

${ }^{39}$ Fundamento de Derecho quinto del Auto de 27 de marzo de 2015 de la Sala Civil del Tribunal Supremo.

${ }^{40}$ Afirmaciones que se obtiene conforme a la jurisprudencia constitucional en particular las SSTC 37/1989, FFJJ 7. 3 y 8 párrafos 3 a 5; STC 35/1989, FJ 8.3 y STC 7/1994, FFJJ 3 y 4. Fundamento de Derecho quinto y sexto del Auto de 27 de marzo de 2015 de la Sala Civil del Tribunal Supremo, conforme a la STC 7/1994. de 17 de enero, en especial, los fundamentos jurídicos 3 y 4. 
biológica y dejar sin efecto su decisión anterior de admisión a trámite de esta demanda.

\section{III.3. Voto particular al auto de la Sala civil del Tribunal Supremo de 27 de marzo de 2014}

El parecer de la mayoría expresado en el Auto de 27 de marzo de 2015 de la Sala Primera del Tribunal Supremo cuenta con el voto particular formulado por el magistrado don José Ramón Ferrándiz Gabriel, al que se adhiere el magistrado don Xavier O'Callaghan Muñoz. Estos magistrados coinciden con la mayoría del tribunal en desestimar el recurso de reposición presentado por la demandante en la medida en que no alega justificación alguna para realizar la anticipación de la prueba ${ }^{41}$. Pero la novedad que supone dejar sin efecto una decisión propia de admisión a trámite de una demanda recaída sobre los mismos hechos y con las mismas razones ${ }^{42} \mathrm{y}$, sobre todo, la improcedencia de la decisión «desde los puntos de vista técnico, empírico y práctico ${ }^{43}$, son objeto de un sólida argumentación jurídica por parte de los magistrados discrepantes. Tres son las principales razones procedimentales e interpretativas expuestas en el voto particular.

En primer lugar, la discrepancia expresada en el apartado tercero del voto particular recuerda los aspectos procesales vinculados a una concepción flexible del principio de prueba orientada al cumplimiento de los fines y derechos constitucionales implicados (artículos 39.2 y $9.3 \mathrm{CE})^{44}$, para a continuación advertir que, en este caso, la estimación del recurso de reposición se basa precisamente en una valoración de la prueba realizada de forma extemporánea ${ }^{45}$. De acuerdo con

${ }^{41}$ Voto particular al Auto de la Sala Primera del Tribunal Supremo 27 de marzo de 2015, apartado VIII.

${ }^{42} \mathrm{Vid}$. al respecto la precisión contenida en el apartado I del voto particular al Auto de 27 de marzo de 2015 de la sala de lo Civil del Tribunal Supremo.

${ }^{43}$ Voto particular al Auto de la Sala Primera del Tribunal Supremo 27 de marzo de 2015, apartado II.

${ }^{44}$ En particular el voto particular recuerda la jurisprudencia constitucional contenida en la STC 7/1994, de 17 de febrero, respecto al alcance del mandato constitucional dirigido a facilitar la investigación de la paternidad. Como también en la STC 138/2005, de 26 de mayo, donde el tribunal expone que «el principio de libre investigación de la paternidad ha de compatibilizarse, necesariamente, con exigencias derivadas del de seguridad jurídica -artículo 9, apartado 3, de la Constitución Española - y de la concurrencia de derechos e intereses legítimos dignos de protección, que derivan de las relacionales paterno-filiales». Voto particular al Auto de la Sala Primera del Tribunal Supremo 27 de marzo de 2015, apartado III.

${ }^{45} \mathrm{Al}$ respecto se afirma que «la Sala no solo podía permanecer pasiva ante las nuevas alegaciones aportadas por la parte recurrente -algunas referidas a hechos 
la naturaleza procesal del recurso de reposición, no resulta jurídicamente adecuado utilizarlo como un instrumento que permita revisar una decisión anterior válidamente adoptada, sobre la base de unos motivos de fondo que sucedieron con posterioridad al momento procesal en que se adoptó la decisión recurrida.

En segundo lugar, el apartado quinto del voto particular recuerda la interpretación flexible mantenida por el Tribunal Supremo sobre el principio de prueba, contrariamente a lo realizado en esta ocasión por la mayoría del tribunal. A juicio de los magistrados discrepantes, si la reiterada jurisprudencia de la Sala se ha apoyado en este criterio flexible y amplio del principio de prueba ${ }^{46}$, este mismo criterio y no otro debía haberse mantenido en esta ocasión, máxime cuando la decisión de la mayoría comparte esa misma concepción flexible. Sin embargo, en el supuesto estudiado, la mayoría del tribunal se aparta de este criterio en un momento procesal inoportuno al considerar que la demanda no debía haberse admitido a trámite por carecer del principio de prueba suficiente. La incoherencia de la argumentación jurídica y del propio proceder del órgano judicial queda así evidenciada.

En tercer lugar, la discrepancia con la mayoría de la Sala se basa en una incorrecta valoración judicial de los medios de prueba aportados por la parte recurrente. Según se expone en el apartado sexto del voto particular, la mayoría realiza un «planteamiento inadecuado del principio de contradicción», que responde «a una visión más ontológica que lógica de la contradicción ${ }^{47}$ de la que se deriva la falta de una apariencia de verdad ante la existencia de contradicciones entre las pruebas iniciales y los hechos y datos aportadas una vez admitida a trámite la demanda. Pero, si en efecto, pueden ser discutibles por incompatibles las pruebas aportadas por la demandante, el tribunal no somete al principio de contradicción los datos aportados en uno y otro momento procesal. No identifica los medidos necesitados de prueba, ni se valora los datos aportados con posterioridad sino para

acaecidos después de la admisión de la demanda y otras a hechos anteriores pero desconocidos por el Tribunal en tal momento-, sino que debía hacerlo, al menos si es que no quería abrir un trámite inexistente y convertir el recurso de reposición en algo distinto de lo que en nuestro sistema procesal es». Voto particular al Auto de la Sala Primera del Tribunal Supremo 27 de marzo de 2015, apartado VI.

${ }^{46} \mathrm{Al}$ respecto, el voto particular cita las SSTS de 12 de noviembre de 1987, 20 octubre 1993; 3 de octubre de 1998; 1 de septiembre de 2004; sentencia 59/2006, de 3 de febrero. Voto particular al Auto de la Sala Primera del Tribunal Supremo 27 de marzo de 2015, apartado V.

${ }^{47}$ Voto particular al Auto de la Sala Primera del Tribunal Supremo 27 de marzo de 2015, apartado VI. 
considerar su incompatibilidad con los presentados inicialmente en la demanda.

En definitiva, la argumentación jurídica expuesta en el voto particular muestra lagunas o contradicciones en el pronunciamiento del Tribunal Supremo en este supuesto particular que deja abierta la cuestión a una eventual demanda de amparo constitucional en defensa del principio de igualdad en la aplicación jurisdiccional de la ley (art. $14 \mathrm{CE}$ ), al apartarse de su decisión anterior, que no parece responder a una argumentación razonada y abstracta de la norma aplicable $^{48}$. Como también podría argumentarse una «quiebra del discurso argumental», "una incoherencia interna que quiebra la lógica argumental del discurso judicial», que de acuerdo con la doctrina constitucional, constituye una de las hipótesis de lesión del derecho a la tutela judicial efectiva (artículo $24.1 \mathrm{CE})^{49}$. Y es que, en efecto, en esta decisión del Tribunal Supremo deja sin efecto una decisión anterior válidamente adoptada por la misma sala del órgano en un momento procesal inoportuno. El tratamiento otorgado al principio de prueba coincidente desde el plano teórico con su reiterada jurisprudencia, pero discrepante desde el plano práctico, y la incorrecta valoración de la prueba presentada conforme al principio de contradicción, constituyen los principales puntos débiles de este pronunciamiento.

\section{VALORACIÓN FINAL}

El análisis de estos pronunciamientos del Tribunal Supremo conduce a unas valoraciones sobre el alcance constitucional de las decisiones judiciales en los juicios de filiación, por cuanto ponen de relieve los fines constitucionales a los que sirven y los derechos fundamentales que pueden verse afectados en la sustanciación de estos asuntos. La singularidad de los casos analizados respecto al sujeto frente al que se dirigen las acciones de filiación, merece igualmente

${ }^{48}$ La doctrina constitucional sobre el principio de igualdad en la aplicación de la ley es muy extensa. Sirvan como ejemplo para este caso, la contenida en la STC 29/2005 FJ 6 y las allí citadas: SSTC 210/2002, de 11 de noviembre FJ 3, 46/2003, de 3 de marzo FJ 2, 70/2003, de 9 de abril FJ 2, 13/2004, de 9 de febrero FJ 2 o 117/2004, de 12 de julio FJ 2.

${ }^{49}$ Como recuerda la STC 29/2005, de 14 de febrero, FJ 5. Doctrina del Tribunal Constitucional sobre la necesidad de que las resoluciones judicial contengan una razonamiento congruente fundado en Derecho. Vid. a modo de muestra las SSTC 214/1999 de 29 de noviembre, FJ 4; 82/2001, de 26 de marzo, FJ 2; 82/2002, de 22 de abril, FJ 7; 224/2003 de 15 de diciembre, FJ 2. 
unas consideraciones finales, pues abordan una dialéctica jurídica tradicionalmente sostenida en el constitucionalismo democrático de Derecho respecto de la virtualidad y alcance de las prerrogativas reconocidas a los titulares de cargos y funciones públicas del Estado.

En efecto, en el marco de la reflexión jurídica sobre estos asuntos ocupa un lugar destacado el debate sobre la concepción y alcance de la inviolabilidad regia. La delimitación temporal de este instituto jurídico a los actos realizados por el Monarca durante el tiempo en que ostente la titularidad de la Jefatura del Estado, junto a la exclusión de la inviolabilidad como causa de inadmisión per se de las demandas de filiación no matrimonial, son acertadamente puestas de relieve en la argumentación del Tribunal Supremo. De acuerdo con estos presupuestos, la prerrogativa traída a la controversia judicial por sí sola, no supone un obstáculo para la valoración de la admisión o inadmisión de la demanda, pues lo determinante es el cumplimiento de los fines constitucionales y requisitos procesales legalmente establecidos para las demandas de filiación. Se advierte en cambio, una laguna en la argumentación del Tribunal Supremo, donde falta un pronunciamiento sobre la delimitación material de esta prerrogativa que, por su vinculación con el ejercicio de las funciones propias de la Jefatura del Estado merece, a nuestro juicio, ser desligada de los actos privados de su titular.

Por otra parte, como se ha constatado, conforme a una consolidada jurisprudencia ordinaria, constitucional y, en el ámbito internacional, por el TEDH, prevalece una interpretación amplia de la noción de vida familiar donde se ampara el derecho de toda persona a buscar el esclarecimiento de su filiación y de protección que merece otorgar a la posiciones de igualdad entre los hijos. Una interpretación jurídica flexible que se aplica tanto en la fase de admisión a trámite como en la fase de prueba de las demandas de filiación. El objetivo de esta concepción amplia no es otro que favorecer el acceso a la jurisdicción, la investigación de la filiación y la garantía de la igualdad entre los hijos, en el marco de la protección que otorga el artículo 39.2 CE por su conexión con los artículos 14 y $24 \mathrm{CE}$. El fundamento de esta lectura flexible radica en los efectos que producen las demandas de filiación para los derechos de los afectados, y que transcienden del ámbito social, moral o cultural de la esfera familiar, y se traducen en un interés material o patrimonial expresado en las obligaciones de alimentos o los derechos sucesorios.

En los supuestos analizados sin embargo, estas cuestiones no son objeto de reflexión o valoración judicial. Las demandas aparecen des- 
de su planteamiento inicial desprovistas de verosimilitud o seriedad, no aportan un principio de prueba suficiente, no superan esa barrera de racionalidad mínima exigida para iniciar la investigación de la filiación. La interpretación flexible de la credibilidad o seriedad de los datos o documentos aportados y de los hechos o circunstancias que sostienen ambas demandas no resulta suficiente para sustanciar los procedimientos de filiación frente a don Juan Carlos I. de Borbón. Los momentos procesales para la adopción de esa misma apreciación judicial son, no obstante, diferentes. En un caso, se procede a la inadmisión a trámite de la demanda pues se advierte ya en esa fase del procedimiento, la debilidad de los argumentos e indicios de prueba aportados por el demandante. El segundo supuesto es, en cambio, más complejo, pues el órgano judicial aprecia la inexistencia sobrevenida del principio de prueba, esto es, una vez admitida a trámite la demanda con ocasión del estudio del recurso de reposición.

Compartimos es este punto, las dudas expresadas en el voto particular al auto de estimación del recurso de reposición, respecto a la debilidades en la fundamentación del Tribunal Supremo. Y es que, la mayoría del tribunal atendiendo a circunstancias acaecidas con posterioridad a la admisión a trámite, realiza una valoración estricta del principio de prueba en un momento procesal extemporáneo, revocando en consecuencia una decisión anterior válidamente adoptada por el mismo órgano judicial. De continuar el procedimiento y atendiendo a las circunstancias y datos existentes, la resolución final de la causa judicial hubiese sido la misma, si bien adoptada conforme al principio de contradicción y en el momento procesal oportuno. 